\title{
Management of dental caries lesions in Latin American and Caribbean countries
}

\section{Amaury POZOS-GUILLÉN(a) \\ Gustavo MOLINA(b) \\ Vera SOVIERO'(c,d) iD \\ Rodrigo Alex ARTHUR(e) \\ Daniel CHAVARRIA-BOLAÑOS(f) \\ Ana María ACEVEDO(g)}

(a) Universidad Autónoma de San Luis Potosí, Faculty of Dentistry, Basic Sciences Laboratory, San Luis Potosí, México.

(b) Universidad Nacional de Córdoba, The Dental Faculty, Department of Dental Materials, Córdoba, Argentina.

(c) Universidade Estadual do Rio de Janeiro UERJ, School of Dentistry, Department of Preventive and Community Dentistry, Rio de Janeiro, RJ, Brazil.

(d) Centro Universitário Arthur Sá Earp Neto - Unifase, School of Dentistry, Petrópolis, RJ, Brazil.

(e) Universidade Federal do Rio Grande do Sul - UFRGS, Dental School, Department of Preventive and Community Dentistry, Porto Alegre, RS, Brazil.

(f) Universidad de Costa Rica, Faculty of Dentistry, Department of Diagnostic and Surgical

Sciences, San José, Costa Rica.

(g) Universidad Central de Venezuela, Faculty of Dentistry, Institute of Dental Research "Raul Vincentelli", Caracas, Venezuela.

Declaration of Interest: The authors certify that they have no commercial or associative interest that represents a conflict of interest in connection with the manuscript.

Corresponding Author:

Amaury Pozos-Guillén

E-mail:apozos@uaslp.mx

https://doi.org/10.1590/1807-3107bor-2021.vol35.0055

Submitted: March 3, 2021

Accepted for publication: March 9, 2021

Last revision: March 15, 2021

\begin{abstract}
Caries management at the lesion level is dependent on the lesion activity, the presence of a cavitation (either cleanable or non-cleanable), and lesion depth as evaluated via radiographic examination. A variety of non-invasive, micro-invasive, and minimally invasive treatment (with or without restoration) options are available for primary and permanent teeth. Non-invasive strategies include oral hygiene instructions, dietary counseling, and personal as well as professional use of fluoridated products that reduce demineralization and increase re-mineralization. Micro-invasive procedures include the use of occlusal resin sealants and resin infiltrants, while minimally invasive strategies comprise those related to selective removal of caries tissues and placement of restorations. Deep caries management includes indirect pulp capping, while exposed pulp may be treated using direct pulp capping and partial or complete pulpotomy. The aim of the present study was to review available evidence on recommended preventive and restorative strategies for caries lesions in Latin American/Caribbean countries, and subsequently develop evidence-based recommendations for treatment options that take into consideration material availability, emphasize ways to adapt available treatments to the local context, and suggest ways in which dentists and health systems can adopt these treatments.
\end{abstract}

Keywords: Dental Caries; Evidence-Based Dentistry; Latin America; Caribbean Region.

\section{Introduction}

The lack of consensus on dental caries management was recently recognized during a discussion between various expert authors from the Latin American and Caribbean countries (LACC), and the aim of this review was to address this gap by developing relevant evidence-based recommendations and strategies that took geographical factors as well as the patient's individual needs into consideration. Therefore, a critical literature review of international evidence, with a specific focus on studies conducted in LACCs, was carried out using a narrative strategy, and the research question of interest was as follows: What are the best treatment options currently available for the management of caries lesions in LACCs?

Dental caries is a multi-factorial, non-communicable, non-infectious, chronic, biofilm-induced disease modulated by various biological, 
behavioral, psychosocial, and environmental factors. ${ }^{1}$ Caries lesions are typically characterized by the active loss of tooth minerals, induced by the metabolic activity of dental biofilm formed by frequent consumption of a sugar-rich diet. In the absence of any intervention, the cumulative effects of alternating demineralization and re-mineralization cycles (favoring the former) leads to the development of a clinically visible lesion, ${ }^{2,3}$ and defensive reactions such as increased intra-tubular dentin formation and initial pulpitis may occur in the dentin-pulp complex upon lesion progression. ${ }^{4}$ When left untreated, caries lesions may slowly progress into the deep dentin and pulpal tissue and, in severe cases, profoundly affect the general health and decrease the quality of life of the patients. ${ }^{5}$ Severe caries lesions represent the primary cause of oral pain and tooth loss globally. ${ }^{6}$

Despite significant advances in oral-health sciences, the World Health Organization have highlighted the high prevalence of dental caries in various developing countries and particularly those in the LACC region where caries represent a major unmet need of the population. ${ }^{7}$ Numerous studies have reported prevalence rates of $40 \%$ to $90 \%$ among children, teenagers, and adults in this geographic region, ${ }^{8}$ and the management of dental caries is often beyond the financial capabilities of low-income countries where limited resources hinder access to high-quality dental treatments. ${ }^{9}$ Therefore, better use of financial resources through the development of evidence-based protocols recommending non-invasive or minimally invasive restorative treatments is essential.

Dental caries need to be managed at the patient and lesion levels. Patient-level interventions include noninvasive strategies that aim to control disease progression and lesions becoming clinically detectable. This can be achieved through dietary counseling and comprehensive oral hygiene measures such as mechanical removal of the dental biofilm through daily tooth-brushing using fluoridated dentifrices which promote re-mineralization by re-establishing the mineral balance between the tooth surface and the surrounding aqueous phase (represented by the saliva and dental biofilm fluid). ${ }^{2}$ However, the success of these interventions is directly dependent on patient adherence to the treatment protocol, and it has been suggested that the best practice for dental caries management should include a more patientcentered model consisting of individualized caries risk assessment and early detection of non-cavitated caries lesions. This approach aims to achieve personalized treatment for the individual patient, and focuses on the treatment and prevention of dental caries at the patient level. ${ }^{10}$

Dental caries management at the lesion level includes a wide range of non-invasive, micro-invasive, and minimally invasive interventions that vary depending on the lesion activity, presence of cavitation (cleanable or non-cleanable), and lesion depth (shallow/moderate/ deep - evaluated using radiographic examination). ${ }^{3}$ These interventions aim to arrest lesion progression, preserve pulpal health by creating a hermetic seal against microbial invasion (through placement of a restoration), and re-establish the tooth's structure and function for as long as possible. ${ }^{11}$ The management protocol for deep caries lesions with a high risk of pulp exposure should include selective removal of caries tissues followed by the placement of new and improved pulp capping biomaterials if necessary. ${ }^{12}$ This contemporary approach to management of caries lesions results in less expensive and more predictable outcomes from the histological and clinical points of view. ${ }^{4}$

Therefore, this review aims to describe current strategies for the management of dental caries at the lesion level for primary and permanent dentition, and make evidence-based recommendations targeting dental practitioners in LACCs.

\section{Strategies for the management of caries lesions: Scientific evidence from LACCs}

A direct comparison of studies was hindered by the lack of consensus on the management of caries lesions and variations in methodologies and study designs adopted. Therefore, prior to commencement of the evidence-based review, the authors first defined the primary objective by means of a set of questions focusing on the management of all caries lesions (ranging from non-cavitated lesions to deep cavities) while taking socioeconomic and cultural factors of LACCs into consideration.

Based on evidence from various clinical trials (some of which were conducted in LACCs), practitioners and health policy-makers should adopt caries management strategies that take the depth of the 
lesion into consideration as these techniques tended to be cost-effective and could, therefore, be adopted by conventional public dental health service in LACCs. This would be particularly beneficial for the enhancement of oral-health care in deprived communities by increasing accessibility to preventive and restorative treatments. Some of the strategies for caries lesion management have been presented below.

Selection of an appropriate strategy should begin with a careful and precise diagnosis at the lesion level. Inactive lesions are typically characterized by the presence of shiny whitish/brownish areas of discoloration on non-cavitated lesions as well as of shiny, smooth, hard on gently probing, and discolored brownish in cavitated lesions reaching dentin. These lesions typically do not require any intervention other than monitoring as they are disease scars, although restorations can be placed in cavitated lesions in order to protect the pulp-dentin complex or restore the tooth's function, form, and esthetics. ${ }^{13}$

Conversely, opaque, rough and whitish tissue on non-cavitated lesions and the presence of soft or leathery (to gently probing) humid and yellowish/ light-brownish tissue in cavitated lesion reaching dentin are clinical signs of active lesions that need to be controlled. Clinicians must be trained to identify early signs of active demineralization which will enable them to intervene in a timely manner using noninvasive and micro-invasive strategies. For cavitated lesions, it is essential to first take into consideration whether the cavity can be cleaned or not as it will help with the decision-making process and selection of the best treatment strategy. Non-invasive strategies are sufficient for the management of cavities that can be cleaned, while those that cannot be cleaned may require a combination of non-invasive, microinvasive, or minimally invasive strategies coupled with restorations. This decision-making process should be biologically informed, evidence-based, and should take the needs of the patient into consideration.

\section{Management of non-cavitated lesions- Non-invasive/micro-invasive strategies}

The primary prevention of dental caries typically involves inhibition of lesion initiation as indicated by the recent consensus on the term dental caries care/management/control as "all actions taken to interfere with mineral loss at all stages of the disease process" This includes primary, secondary, and tertiary preventive measures that incorporate both non-operative and operative treatments. ${ }^{1}$

Disease triggering factors must be controlled in order to prevent formation of caries lesions and arrest progression of existing ones. Therefore, preventive strategies should take biological, behavioral, psychosocial, and environmental factors into consideration in order to avoid negatively affecting the oral environment. ${ }^{14}$ Oral hygiene measures, dietary counseling, and other non-invasive strategies (such as the application of fluoride and chlorhexidine varnishes and the use of xylitol lozenges) have been shown to be effective in controlling active non-cavitated lesions in children. ${ }^{15}$ Some of these strategies will be reviewed in the subsequent section to highlight the need for simultaneous management of the disease and lesion.

Various experimental and clinical studies have demonstrated that caries lesions originate in the enamel or exposed root dentine beneath accumulated and stagnated dental biofilms. The dental caries process initiation and progression depend on the metabolic activity of the dental biofilm which, in turn, is enhanced by frequent intake of dietary sugars. Therefore, regular and meticulous mechanical removal of the dental biofilm aids in arresting lesion progression. ${ }^{16}$ However, previous studies have shown that personal oral hygiene protocols (by means of supervised tooth-brushing) lacking fluoride administration, either via dentifrices or community-based methods, were effective in controlling gingivitis but failed to prevent coronal caries in children aged 10-13 years old. ${ }^{17}$ This reinforces the importance of fluoridated products (e.g. dentifrices) and/or community-based methods for fluoride delivery in lesion control.

The selection of appropriate strategies for the prevention of lesion formation and inhibition of disease progression can be challenging for the dental professional, and the decision-making process should be based on scientific evidence focusing on when and how to implement the strategy while taking the needs of the patient and the availability of financial and technical resources, especially in public health systems, into consideration. Selection of multiple 
strategies may be necessary, and the risk of caries exhibited by the patient may even be considered on the decision-making process. ${ }^{18}$

The recent global decrease in the prevalence of dental caries can be attributed to the widespread use of fluoride-containing dentifrices, ${ }^{19,20}$ with numerous clinical studies showing that mechanical removal of the dental biofilm by daily tooth-brushing using fluoridated dentifrices in concentrations of 1,0001,500 ppm F significantly contributed to controlling enamel, dentin, and/or root caries lesions. ${ }^{20-23}$ Moreover, tooth-brushing twice a day using fluoride dentifrices at concentrations of 5000 ppm F was shown to be more effective in arresting root caries in the elderly population compared to dentifrices with concentrations of 1,000-1,500 ppm F. ${ }^{23,24}$ Professional dental biofilm management should be also considered as a treatment option for dental caries.

In addition to dentifrices, a wide range of topical fluoride-based agents are available for individual use, ${ }^{25}$ including high-concentration fluoride products (such as acidulated phosphate gels, varnishes and solutions) which allow deposition of greater amounts of calcium fluoride globules onto the tooth surface forming fluoride reservoirs in the oral cavity. Progression of non-cavitated caries lesion in primary and permanent teeth can be significantly controlled by $5 \% \mathrm{NaF}$ varnishes, ${ }^{26}$ while $38 \%$ silver diamine fluoride (SDF) represent a more effective strategy for the control of cavitated caries lesions reaching dentine when compared to other active treatments (e.g. atraumatic restorative treatment (ART) restorations or $\mathrm{NaF}$ varnish). ${ }^{27} \mathrm{SDF}$ has also been shown to be effective in inactivating root caries lesions..$^{24,28,29}$

Among non-fluoridated agents, casein phosphopeptide-amorphous calcium phosphate (CPP-ACP) is a bioactive agent that has been shown to be effective in re-mineralizing tooth structures in vitro and in vivo. A recent meta-analysis suggested that $\mathrm{CPP}-\mathrm{ACP}$, conventional fluoride toothpastes, and fluoride varnishes had similar efficacy with regard to controlling lesion development, and clinical parameters such as enamel micro-hardness, DMFS/dmfs (decayed, missing, filled surfaces) index scores, and Enamel Decalcification Index scores did not differ significantly between CPP-ACP and fluoride products. ${ }^{30}$ Moreover, a combination of CPP-ACP and fluoride varnish was shown to have superior anti-caries effect, particularly in enamel lesions on young permanent teeth, as CPPACP could carry fluoride ions deeper into the lesions, enhancing re-mineralization. Nevertheless, there is insufficient evidence on whether CPP-ACP agents are more effective in controlling caries lesions when compared to fluorides, and high quality, well-designed randomized controlled trials are necessary. ${ }^{30}$

The cariostatic effects of non-fluoridated chemical agents such as arginine, chlorhexidine, triclosan, and xylitol have been evaluated in vivo and compared with conventional fluoride in several randomized controlled trials. A recent systematic review compared the efficacy of non-fluoridated agents and fluoride in controlling caries in primary teeth and found no evidence of the former being superior. However, this could be attributed to a high risk of bias in most studies reviewed, ${ }^{31}$ and well-designed randomized controlled trials are necessary in order to make conclusive recommendations. Chlorhexidine varnish was found to be more effective in controlling root caries lesions compared to placebos, and the results were consistent. ${ }^{32}$

An in vitro study examined the use of theobromine (3,7-dimethylxanthine), a primary alkaloid derived from the cacao plant commonly found in LACCs, as a re-mineralizing component of dentifrices and found it to be less effective than those containing fluoride. ${ }^{33}$

The use of nanotechnology to enhance the anticaries effects of dentifrices, varnishes, surface coating agents, and fluoride-releasing materials have also shown promising results, with the use of oral medicine nanosystems for individual prophylaxis showing significant progress with regard to ensuring bacterial symbiosis and maintaining good oral health. Nano-particles have also been integrated into various cosmetic products targeting enamel re-mineralization, thus creating opportunities for new research into the development of enhanced delivery systems that serve as carriers for minerals and/or biomaterials. Their clinical use for control of caries lesions remains under evaluation. ${ }^{34}$

Current evidence also recommends the use of pit and fissure sealants as a micro-invasive strategy for the prevention and control of caries lesions..$^{24}$ Resinbased fissure sealants act as a physical barrier between the tooth surface and the stagnated dental biofilm and 
successfully reduce the onset and progression of occlusal caries lesions, particularly in permanent molars. ${ }^{35}$ This evaluation is largely based on evidence that shows that sealing a lesion reduces the bioavailability of nutrients to microbial growth, thus preventing disease progression up to $70 \%$ in non-cavitated occlusal lesions when compared to no sealing. ${ }^{35,36}$ Moreover, sealants are more effective in arresting active non-cavitated occlusal lesions when compared to fluoride varnishes, although there is still no clear evidence on the best sealant (resinbased or glass ionomer). ${ }^{37}$ However, the questionable integrity and stability of sealants placed on occlusal lesions that appear non-cavitated clinically but extend into the middle or inner dentine radiographically should be taken into consideration, and a minimally invasive restorative strategy (as described below) should be adopted in such cases. ${ }^{13}$

In contrast to sealants, resin infiltration acts as a barrier not on the tooth surface but within the caries lesion. Filling the enamel lesion, the resin can occlude the porosities, thus preventing the lesion progression by avoiding the penetration of the acids originated in the dental biofilm located on the external tooth surface. Previous studies have shown that resin infiltration is more effective in controlling non-cavitated proximal caries when compared to other non-invasive approaches, both in primary and permanent teeth. ${ }^{38,39}$

\section{Management of cavitated dentine lesions}

As mentioned above, the decision-making process for the management of active cavitated lesions is dependent on whether the cavity can be cleaned (where mechanical biofilm removal can be carried out at home by tooth-brushing) or not. The former can be managed non-invasively, and it is assumed that the disease process is halted and lesion progression is arrested upon adequate removal of the biofilm. Accessibility for adequate cleaning can be increased by slightly widening the cavity margins to remove overhanging enamel/dentine. ${ }^{40}$ However, patient motivation is crucial in this case, and regular monitoring for proper mechanical removal of biofilm is essential. This is particularly applicable in the case of primary dentition where the child's oral hygiene is the responsibility of their parents or caretakers who must also be adequately informed and motivated. Periodic clinical examination is necessary for assessment of lesion activity, and treatment success is achieved once the remaining tissues become hard indicating halting of lesion progression. The use of $38 \%$ SDF solution (applied biannually) as an adjunct to mechanical biofilm removal may be recommended for the management of coronal cavitated caries lesions in primary ${ }^{25}$ and permanent dentition. ${ }^{3}$ Not all cleaned cavities require restorations, and this method is usually preferred when there is a need to protect the pulp-dentin complex or restore the tooth's function, form, and esthetics..$^{13}$

In contrast, active cavitated lesions that cannot be cleaned, such as those on proximal or other poorly accessible surfaces, are understood to be prone to progression and, therefore, may require restorative procedures facilitating dental biofilm control. Cavities on proximal surfaces or in any other surfaces where the biofilm cannot be properly removed should be assessed by visual-tactile methods (with the aid of tooth separators in the case of proximal surfaces) and/or by bitewing radiographs to assess depth. Proximal cavitation on lesions restricted to the enamel only are unlikely, while lesions extending to the enamel-dentin junction or to the outer third of the dentin may or may not be cavitated and those extending into the middle or inner third of the dentin are likely to be cavitated. Non-cavitated lesions should be managed using non-invasive or microinvasive interventions as described in the previous section, while cavitated lesions that are difficult to clean should be managed as described below. ${ }^{13}$

Cavitation indicates severe contamination of the dentin with cariogenic microorganisms, although arresting lesion progression is possible through adequate sealing that stopped further microbial growth. ${ }^{41}$ Therefore, removal of all caries tissues in order to reach a hard and virtually cleaned and disinfected remaining dentin (non-selective removal of caries tissue up to hard dentin or NSRHD) is no longer promoted, and several strategies for the management of non-cleanable cavitated lesions with dentinal involvement have been presented below. However, it is important to highlight that these are applicable only in case of absence of spontaneous pain, signs of pulpal exposure or irreversible pulpitis, or radiographic evidence of periapical lesions. 
Cavitated lesions with dentinal involvement can be managed without prior removal of caries tissue tissues. The Hall technique, which involves placement of a preformed metal crown on decayed cavities without tooth preparation (as a mixed non-invasive and restorative treatment) and anesthesia, has been shown to have high success rates in occlusal and occluso-proximal lesions arrestment in primary molars ${ }^{42-44}$ particularly when compared to conventional restorative treatments over 2-5 years of follow-up. ${ }^{43}$

Upon comparing direct placement of resin sealants or flowable resin composites without prior removal of caries tissues (as a mixed micro-invasive and restorative treatment) to conventional composite restorations placed after selective removal to firm/ leathery dentine, the two were seen to exhibit similar efficacy with regard to controlling lesion progression in occlusal cavities of primary molars radiographically shown to extend to the outer half of the dentine after 18 months and 2 years of follow-up. ${ }^{45,46}$

Additionally, placement of resin sealants without prior caries tissue removal and conventional resin composite restorations (conducted after removal of all caries tissue) exhibited comparable efficacy on lesions arrestment after 2-3 years ${ }^{47}$ and 3-4 years ${ }^{48}$ of follow-up of permanent posterior teeth with occlusal lesions (mostly cavitated in enamel and dentin and radiographically shown to extend up to two-thirds of the dentin) requiring restoration. In addition to controlling lesion progression, the placement of resin sealants over caries tissues allows deposition of tertiary dentine on the sealed cavities, thus inducing hardening of the remaining caries tissues. ${ }^{47,48}$ An overall comparison of the materials used above showed that flowable resins exhibited survival times that were similar to composite resin restorations. ${ }^{46}$ Several studies have reported partial or total loss of resin sealant retention over the studied period, ${ }^{45,47,48}$ highlighting the importance of regular follow-up visits for clinical monitoring. The appropriate use of sealants/flowable resins directly over caries tissues in cavitated lesions extending up to the middle third/half of the dentine can postpone the need for more invasive restorative treatments and reduce the need for tissue removal, thus preserving tooth structure. However, further studies in this field are still necessary before a definitive recommendation can be made.

When removal of dentinal caries tissue is unavoidable, it should be kept as minimally invasive as possible to allow good sealing between the restoration and surrounding cavity walls and adequate placement of the restorative material. Moreover, preservation of the tooth structure, maintenance of the pulpal health, and avoidance of pulpal exposure are crucial. ${ }^{11}$ It is important to reinforce here that irrespective to the selective removal of carious tissue over the pulp roof (as described below), hard tissue should be left at the cavity surrounding walls (whose tactile characteristics are similar to sound dentin) using hand and/or rotatory instruments for allowing a proper bonding and sealing of the restorative materials with cavity walls. Taking the depth of the lesion and hardness of the remaining dentin into consideration, caries tissues should be removed based on the following recommendations: $:^{11}$

a. Shallow to moderate deep lesions where the radiolucency extends to the outer pulpal twothirds or three-quarters of the dentine (estimated using a bitewing radiograph): selective removal to leathery/firm dentin (SRFD), retention of leathery/firm caries tissue resistant to hand excavator over the pulpal roof, and completion of restoration in one session;

b. Deep lesions where the radiolucency extends to the pulpal third or quarter of the dentin (estimated using a bitewing radiograph): selective removal to soft dentin (SRSD; easily scooped up with a sharp hand excavator) so as to leave some soft caries dentinal tissue over the pulpal roof to reduce the risk of pulp exposure, followed by completion of restoration in one session. For many years, stepwise excavation (SW) was the treatment of choice for such deep lesions. It consisted of caries excavation in two steps, wherein SRSD and temporary restorations were carried out initially, followed by a second round of caries tissue excavation up to firm/hard dentin over the pulpal roof after several months. However, this treatment is no longer being advocated for primary teeth. ${ }^{49}$ 
Restoration of the cleaned cavity can be carried out using chemically activated high-viscosity glassionomer cement (HV-GIC), commonly indicated for ART restoration where the caries tissue is removed with hand instruments only. The decision to remove dentin up to soft or firm consistency over the pulpal roof depends on the lesion depth. A margin of sound dentin (hard tissue) should be retained on the surrounding cavity walls to allow proper sealing, and a sharp hand excavator may be used to widen the entrance of small cavities by removing overhanging enamel. A recent meta-analysis reported high survival rates for single-surface ART restorations carried out using HV-GIC in primary (94.3\% over 2 years) and permanent (87.1\% over 3 years) posterior teeth. The survival rates for multi-surface restorations were lower in primary (65.4\% over 2 years) and permanent teeth (77\% over 5 years), although "cavity size" and "cavity depth" were not taken into consideration. The authors concluded that there was insufficient evidence to draw definitive conclusions regarding the survival of multi-surface ART restorations placed on permanent teeth. ${ }^{50}$ However, the success of this strategy is directly dependent on the restorative material used. Two clinical trials concluded that ART restoration of primary molars using low-cost GIC presented lower success rates over 1-2 years of follow-up when compared to conventional HV-GIC, 51,52 suggesting that the overall cost of treatment may be increased by the need for re-interventions and replacement of defective restorations. ${ }^{52}$ These studies suggest that ART restoration using a high-quality material represented a suitable treatment option for coronal caries lesion management, particularly for single-surface restorations.

Concerns regarding pulpal vitality and the longevity of restorations placed over remaining caries tissues may be raised, especially after selective tissue removal in deep cavities. A similar success rate (assessed both clinically and radiographically) was observed over a 2 year follow-up period for both techniques [selective removal of caries tissue (92\%) and NSRHD (96\%)] conducted on deep lesions in primary teeth, ${ }^{53}$ although the occurrence of pulpal exposure and overall operative time were lower during selective caries tissue removal compared to
NSRHD..$^{53}$ Moreover, restoration survival was lower for selective removal of caries tissue (66\%) compared to NSRHD (86\%). ${ }^{54} \mathrm{~A}$ recent systematic review and meta-analysis reported a greater risk of failure for restorations placed after SRSD on primary teeth when both occlusal and occluso-proximal restorations were analyzed together, ${ }^{55}$ although the limited number of studies included along with their high risk of bias prevented formation of definitive conclusions..$^{55}$ Nevertheless, dentists should not be discouraged from conducting selective removal of caries dentine on deep lesions of primary teeth as this approach allows avoidance of more invasive interventions. Shorter intervals between recall visits to evaluate the quality of restorations has been recommended..$^{55}$ A multicenter randomized controlled trial examining permanent teeth for a period of 5 years in public health services and public universities in Brazil showed that pulpal necrosis was less likely to occur after SRDS than after SW on molars presenting deep cavitated lesions radiographically shown to extend beyond the inner half of the dentin thickness. ${ }^{56}$ Similar success rates (in terms of pulp vitality) were observed between complete SW (75\%) and SRSD (80\%) but the success rate of SRSD was higher when both complete and incomplete SW treatments were combined (56\%). The authors also reported very low success rates (5\%) for incomplete SW, and emphasized that the success of SW is highly dependent on patient commitment to recall visits. Furthermore, as recall visits for SW are associated with cavity re-opening and placement of long-lasting restorative materials, the risk of pulpal exposure during the second step of excavation and related treatment costs and patient discomfort are higher. Additionally, SRSD and restoration in one session exhibited higher success rates with regard to maintenance of pulpal vitality in permanent molars when compared to SW and NSRHD. ${ }^{57}$ Given the low risk for pulp exposure, the high success rates in terms of maintenance of pulp vitality over time, and the lower operative time, selective removal of caries tissue followed by definitive restoration in a single visit a recommended strategy for less invasive management of deep lesions. With regard to the longevity of restorations, a 3 year retrospective study examining restoration survival in young permanent 
molars of children at a high risk of caries reported similar outcomes for both selective removal of caries tissue and NSRHD. ${ }^{58}$ Poor oral hygiene and multisurface restorations (involving three or more surfaces) were regarded as risk factors for restoration failure..$^{58}$ Additionally, restorations placed after SRSD (79\%) and SW $(76 \%)$ exhibited similar success rates after 5 years of follow-up. ${ }^{59}$ Generally, resin composite restorations are superior than resin-modified glassionomer cements (RM-GIC) $)^{58}$ and similar to amalgam restorations in terms of longevity. ${ }^{59}$ Fracture, loss of marginal integrity, wear, and partial or total loss were the most common reasons for restoration failure, ${ }^{55,59}$ and recent studies have suggested that a high risk for developing of caries lesions and the presence of active caries lesions are condition that negatively impact restoration longevity. ${ }^{58,60}$

Dental restorations tend to undergo deterioration and degradation over time, making regular clinical assessments for localized repair or complete replacement if necessary. Restoration replacements often lead to loss of tooth structure, making the tooth remnants more fragile and increasing the risk of harm to pulpal tissue. Hence, attempts to repair defective restorations (e.g. by sealing localized marginal defects, polishing, re-contouring) should be considered before opting for immediate replacement. In case of restoration repair, any caries tissue around the defective part should be removed. A retrospective study demonstrated that the repair of defective resin composite or RM-GIC restorations in primary teeth increased their longevity over 3 years, even in highrisk children. ${ }^{61}$ Moreover, repaired resin composites (presenting localized defects up to $3 \mathrm{~mm}$ diameter and restricted to the occlusal surface) and amalgam restorations (presenting localized marginal defects not wider than $1 \mathrm{~mm}$ and restricted to the occlusal surface) acted similarly in terms of marginal integrity and demineralization around the restoration when compared to new restorations in permanent molars over a 10 year follow-up period. ${ }^{62,63}$ The anatomy and color of resin composites and marginal staining in case of amalgam restorations were also similar between repaired and replaced restorations, indicating that the former were clinically acceptable even after 10 years. ${ }^{63,64}$ These studies suggest that restoration repair increases the longevity of restorations and should be preferred and encouraged where possible. Table shows a summary of studies examining caries management in LACC. $22,45,46,48,51,52,53,56,58,59,64,65,66,67,68,69,7$ 0,71,72,73 Figure 1 shows a decision-making diagram for the management of non-cavitated and cavitated dentine lesions in the context of LACCs. These recommendations are intended to assist clinicians and stakeholders in the decision-making process, and it is important to re-emphasize that strategies should be selected based on clinical judgment as well as the patient's needs.

"Ultra-conservative Treatment" (UCT) of caries lesions often involves placement of bound and sealed restorations directly over frank cavitated lesions extending into the dentine. ${ }^{1}$ However, it may also include combined use of ART restorations for small cavitated lesions as well as enlargement of medium-sized cavities to facilitate biofilm removal under supervised toothbrusing. ${ }^{22}$ These variations in definitions and approaches associated with UCT increased the risk of misunderstanding and as a result this terminology was not included in the present manuscript.

\section{Management of deep caries lesions with exposed pulpal tissue}

To avoid further compromising the pulpal tissue, deep caries lesion management should follow scientifically proven approaches. However, in many cases the depth of the caries cavity may not be as conservative as expected, resulting in pulpal exposure which may be either strictly iatrogenic (mechanical exposure of pulp tissue after caries removal) or caused by the severity of the dental caries per se.

Initial clinical and radiographic examination is essential in order to avoid possible pulpal exposure during the management of deep cavities. The presence of spontaneous pain, tenderness to thermal stimuli, or painful occlusal contact may indicate the extent of pulpal inflammation, although a complete absence of symptoms in the presence of profound damage is often more worrying. In such cases, the two possible diagnoses include pulpal necrosis or asymptomatic irreversible pulpitis. In case of necrosis, the patient must be informed immediately and a complete 


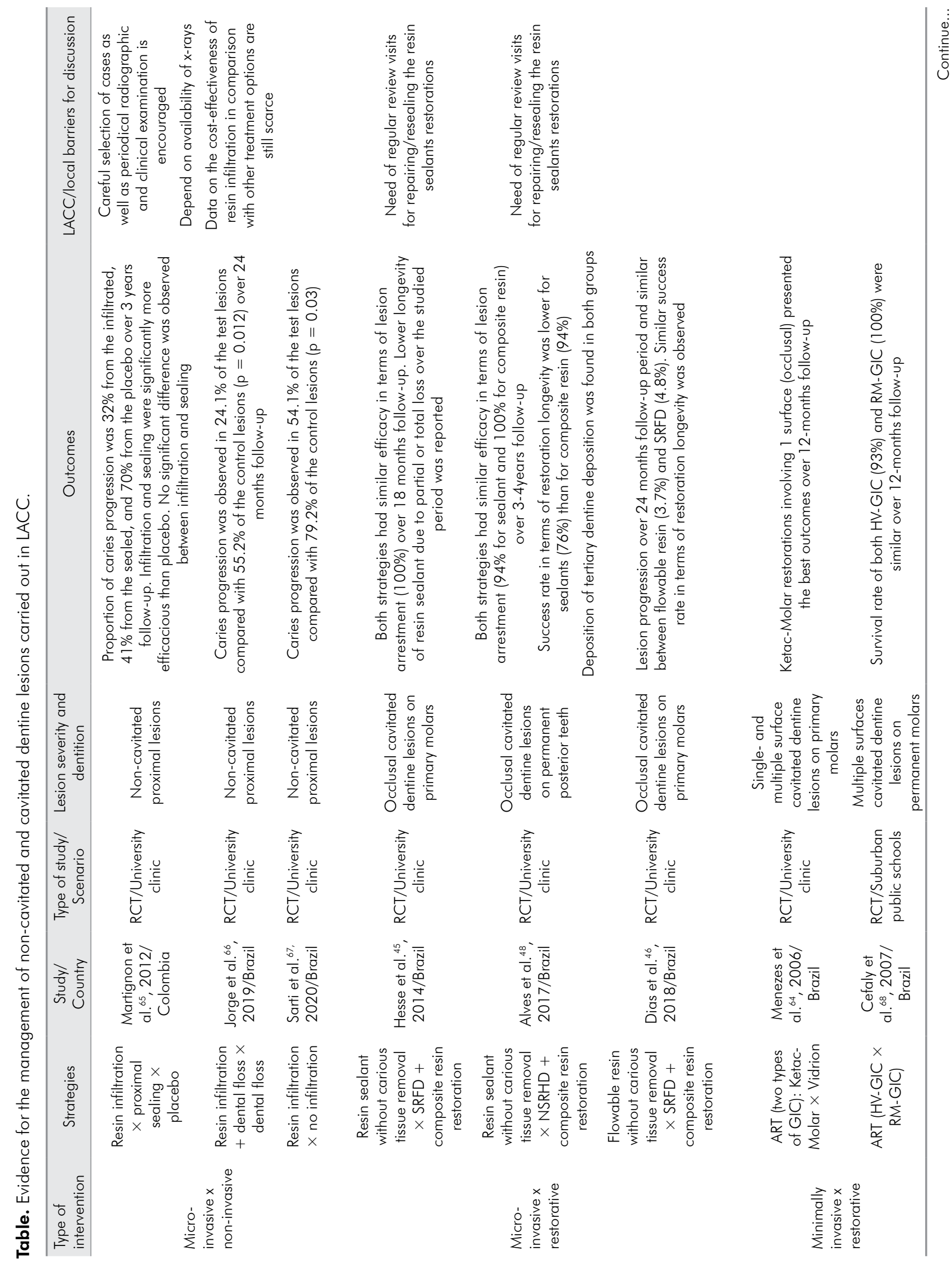




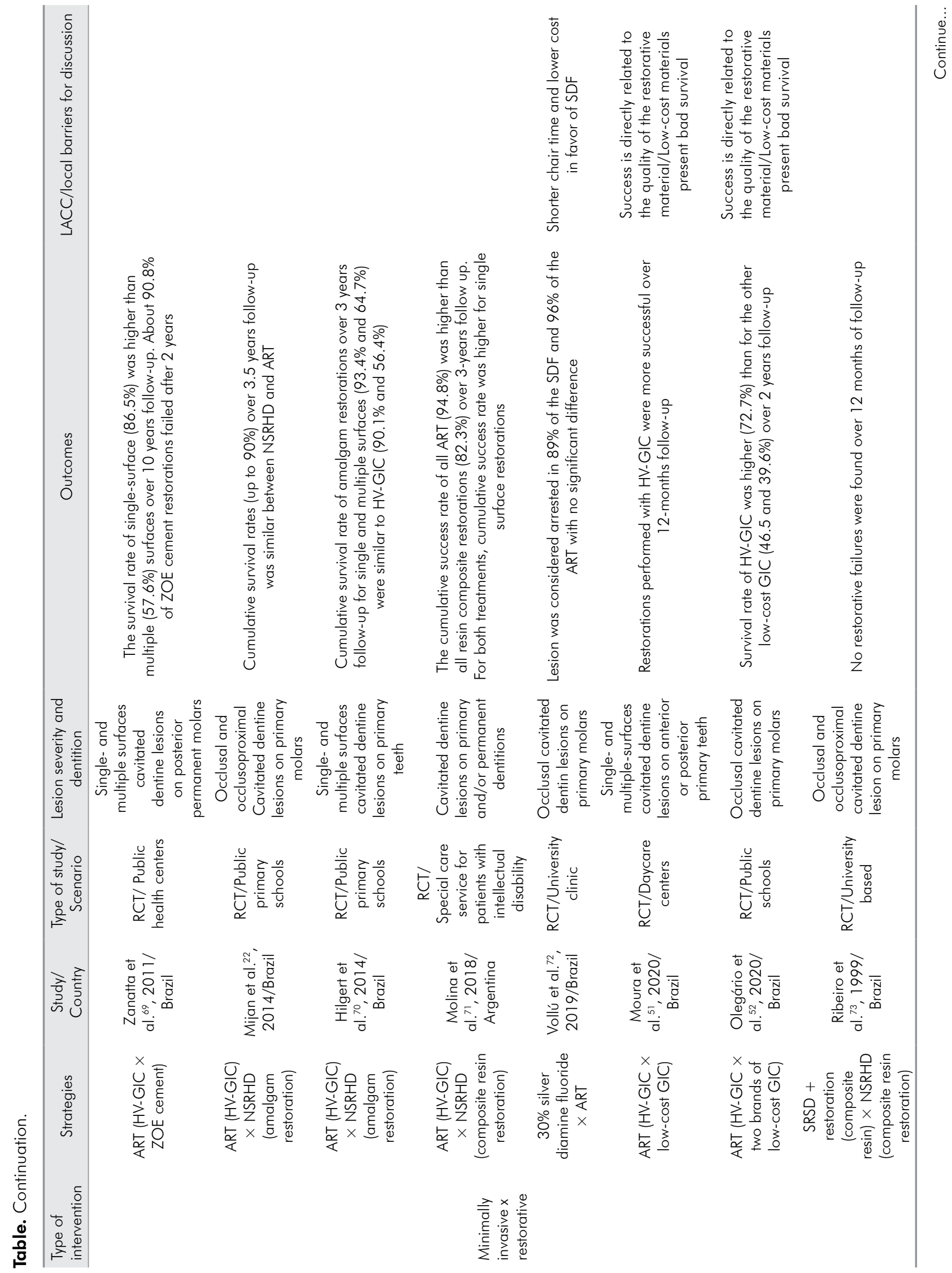



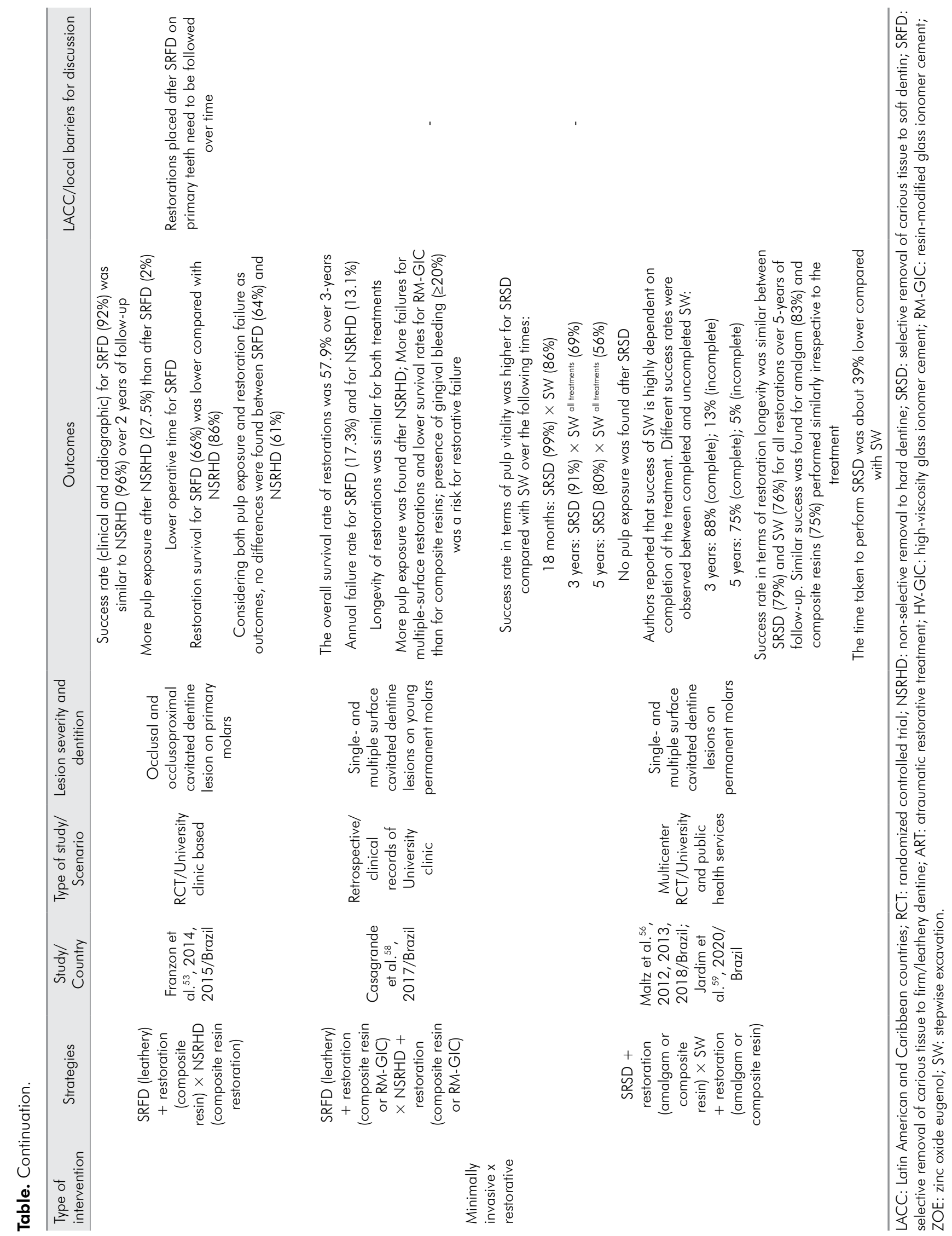
Strategies for caries lesion management

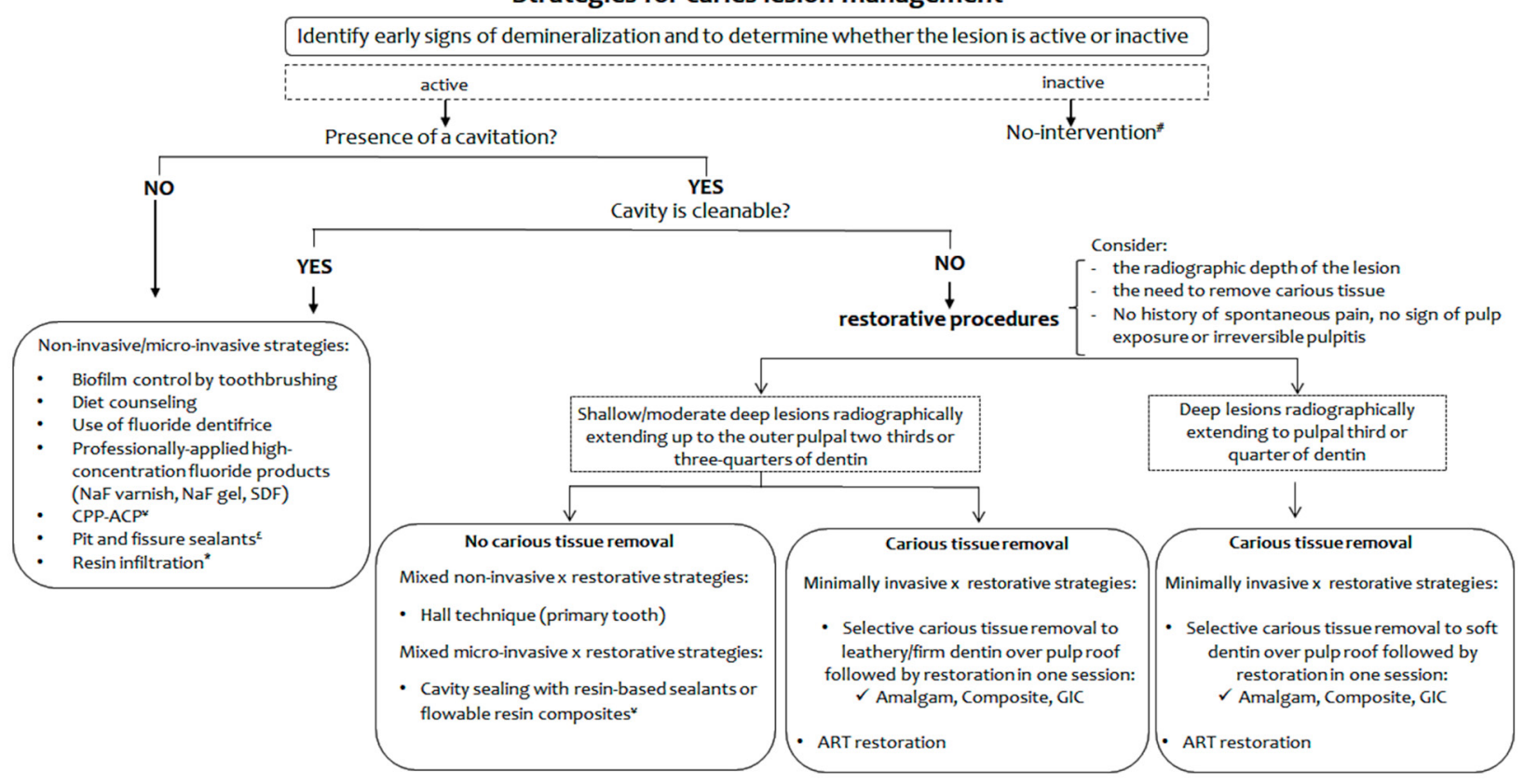

Figure 1. Decision-making flowchart for the management of non-cavitated and cavitated lesions adapted to the LACC context. NaF: sodium fluoride; SDF: silver diamine fluoride solution; CPP-ACP: casein phosphopeptide-amorphous calcium phosphate; ART restoration:

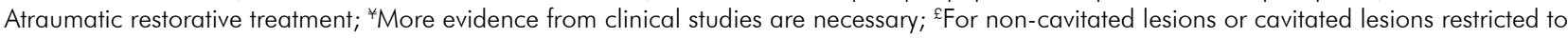
the enamel. Dentinal involvement of occlusal lesions must be assessed using bitewing radiographs; "For non-cavitated lesions only; ${ }^{\#}$ except for inactive cavitated lesions requiring protection of the pulp-dentin complex and recovery of the tooth's function, form, and aesthetics.

invasive root canal treatment must be conducted prior to placement of a restoration.

Once pulp vitality is confirmed and possible pulpal compromise is recognized, the clinician must try to preserve the pulpal health status as much as possible. Selective removal of caries tissues in deep caries lesions may result in $i$ ) close proximity to the pulp tissue, ii) direct exposure of the superficial dental pulp, or iii) deeper pulpal involvement. The most common treatment measure for the first scenario often adopted in LACCs involves the use of liners or base materials (indirect pulp capping) such as calcium hydroxide pastes or glass-ionomer cements followed by direct restoration using bioactive composites. ${ }^{74}$ However, recent studies have questioned the benefits of calcium hydroxide liners, and have suggested that a possible overestimation of their clinical benefits may have occurred. ${ }^{41,75,76,77}$

Exposure of the superficial pulp will require manipulation of the tissue and different kinds of vital pulp treatment (VPT), including direct pulp capping and partial or complete pulpotomies using bio-ceramic materials. Direct pulp capping is typically recommended for class I (no prior presence of a deep caries lesion; pulp exposure surrounded by sound dentine; expectation that the underlying pulp tissue is healthy) or class II (preoperative presence of a deep caries lesion; pulp exposure judged to have occurred in a zone of bacterial contamination; expectation that the underlying pulp tissue is inflamed) lesions ${ }^{78}$ and is preferred over complete root canal treatment. However, its feasibility depends on local clinical findings such as adequate bleeding control and extension of the exposure. Hemostasis and disinfection can be successfully achieved by cleaning the wound with sodium hypochlorite, although other irrigating solutions such as chlorhexidine may also be used. ${ }^{4}$ Although this intervention is typically recommended for permanent dentition, recent evidence also supports its use in primary teeth with promising results. ${ }^{79}$ Although calcium hydroxide is the most commonly used material for VPT, the introduction of calcium 
silicate-based cements such as mineral trioxide aggregate (MTA) and tricalcium silicate cement (Biodentine) increases possibilities with regard to clinical performance. A recent clinical trial that compared calcium hydroxide, MTA, and Biodentine for direct pulp capping demonstrated similar clinical outcomes for all three materials, with calcium silicate offering certain clinical advantages such as improved manipulation and acceptable setting time..$^{80}$

Circumstances where the inflammation process has spread beyond the pulp exposure and the bleeding is not reddish on clinical observation, conventional root canal treatment and further restoration may be the treatment of choice. This is a popular treatment procedure as it provides positive outcomes and allows immediate control of the patient's symptoms. However, recently introduced treatment alternatives with promising outcomes include a mid-step treatment involving partial or complete pulpotomy instead of a complete root canal for permanent teeth. ${ }^{81}$ Although pulpotomies are frequently used in primary teeth, the application of calcium/silicate cement offers a suitable alternative for the treatment of deep caries lesions with exposed pulp. Interestingly, a systematic review comparing partial/full pulpotomies with direct pulp capping in permanent teeth showed that the former provided more predictable outcomes.$^{82}$ Specifically, partial pulpotomies were seen to exhibit high success rates in exposed caries permanent molars up to 2 years post-operatively. ${ }^{83}$ Recent evidence shows that full pulpotomies obturated with Biodentine resulted in immediate pain relief and presented excellent clinical and radiographic outcomes after one year, even in cases previously diagnosed with symptomatic irreversible pulpitis. ${ }^{84}$ Figure 2 shows a decision-making diagram for pulp protection and the management of exposed pulp in deep caries lesions in the context of LACCs.

There are a wide range of treatment options for pulp protection and the management of exposed pulp; however, some of these options remain controversial and their success depends on the practitioner's clinical skills as well as the availability of modern equipment and bioactive materials (often limited in LACCs). Greater global efforts and further research are essential in order to improve access to the most current technologies and achieve standardization of treatment options for both primary and permanent teeth.

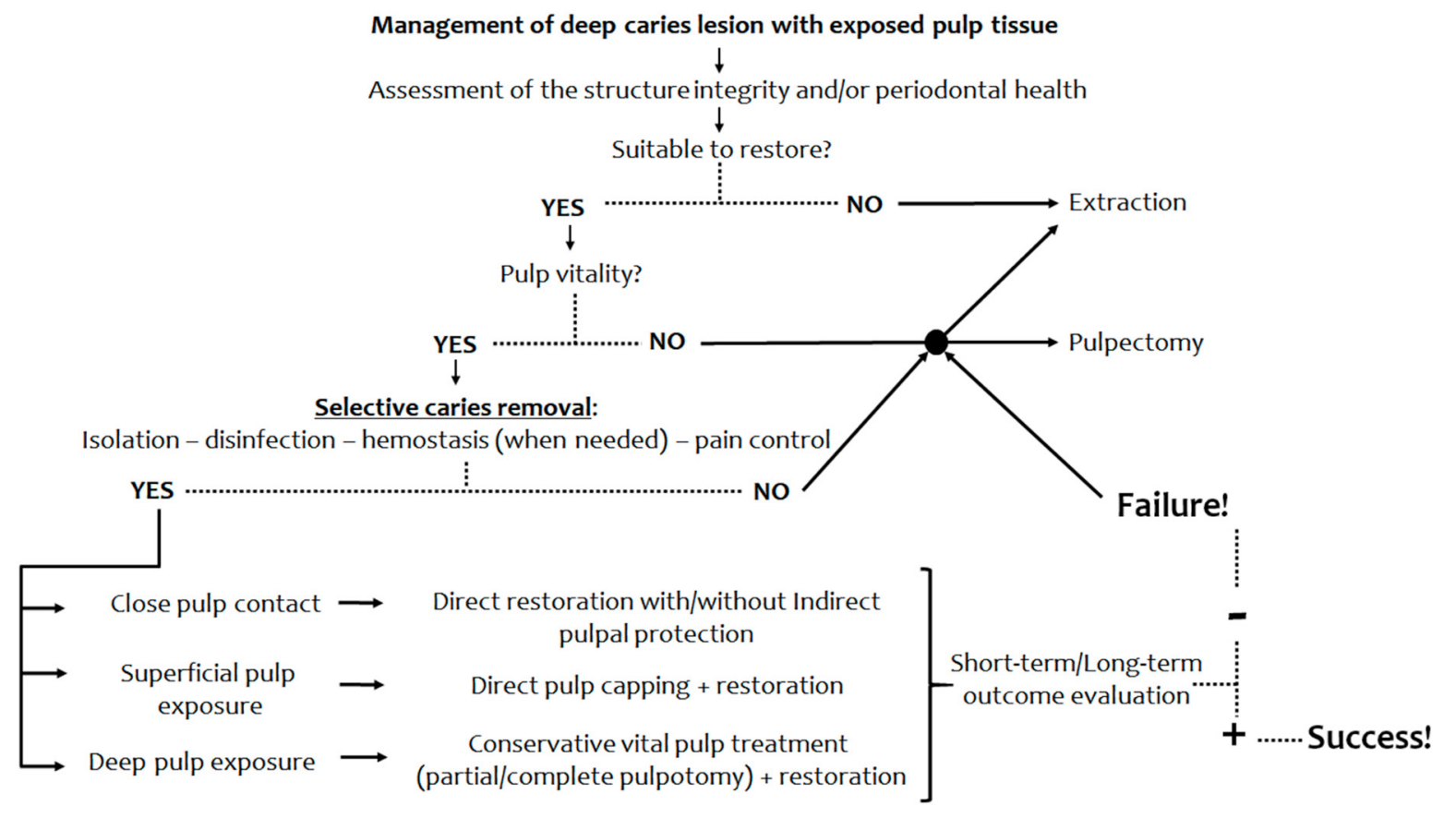

Figure 2. Decision-making flowchart for treatment of deep caries lesions compromising the dental pulp. Strategies for the treatment of primary dentition must be adapted to the patient's age, their orthodontic and exfoliation status, and the risk of affection of the subjacent permanent teeth. 


\section{Social perspectives and challenges of caries lesion management in LACC}

Accurate diagnosis of caries lesion activity and extension is crucial for selection of the best management strategy. Caries lesions can be appropriately managed and tooth functionality can be preserved long-term with the help of less invasive strategies that take caries biology as well as the individual patient's socioeconomic circumstances into consideration. LACC clinicians can restore the health and esthetics of primary or permanent dentition satisfactorily using a range of treatment options, and the implementation of adequate oral care services can help overcome the majority of associated challenges despite limited public resources in these countries. Modern dental academics institutions and clinical practitioners are encouraged to reshape their approach to caries lesion management by adopting evidence-based practice, and prioritization of cost effective, feasible, less invasive, and safer strategies that are wellsupported by published evidence is essential. The knowledge and application of these management approaches may help address persisting barriers to change and minimize the unnecessary use of more invasive interventions.

Although the prevalence of dental caries in permanent teeth among adolescents is decreasing in LACCs ${ }^{85}$ it remains a relevant public health problem as more than half of the population of 12-year-old adolescents exhibit one or more cavitated caries lesions. No significant decrease in caries prevalence has been observed among primary teeth since the year 2000, and efforts to control the disease should be focused on lower socioeconomic strata that exhibit the highest prevalence. ${ }^{85}$ These strategies must be cost effective and based on reliable evidence.

Assessment of the cost-effectiveness of any strategy aimed at the management of untreated caries lesions, which are increasingly prevalent among high-risk populations, is essential in order to reduce the financial burden in LACCs. These should be evidence-based and range from early preventive interventions to the management of non-cavitated and cavitated caries lesions. With regard to community-based strategies, programs such as water and salt fluoridation have been shown to be economically beneficial, with
DMFT scores decreasing drastically in the Chilean population after 6 years of program implementation. ${ }^{86}$ Moreover, both water and salt fluoridation were also reported to be cost effective, with the latter being slightly superior to the former.

Strategies that combine biological approaches with the best preventive practice $(\mathrm{B}+\mathrm{P}$; based on either non-caries tissue removal or selective caries tissue removal followed by restoration) for the management of caries lesions in the primary dentition have been found to be the most cost effective in studies conducted in developed countries. ${ }^{87}$ Although clinical trials using similar approaches have been conducted in deprived communities in LACCs, ${ }^{22}$ evidence on their costeffectiveness is still scarce. Conversely, controversial results regarding the cost-effectiveness of preventive measures for first permanent molars have shown some dependency on the application of fluoride varnishes and pit and fissure sealants. ${ }^{88,89}$ Regardless of the strategy, any of these resources should be advisable for high-risk patients.

The best strategies for the management of dental caries, a multifactorial disease, address a range of issues instead of focusing on isolated management options only. Therefore, structured preventive programs such as CMS (Caries Management System: based on regular monitoring and non-invasive management for the control of lesion progression and promotion of re-mineralization in non-cavitated lesions); ${ }^{90}$ BPOC (Basic Package of Oral Care that is recommended for deprived communities and is based on ART and widespread use of affordable fluoride dentifrices); ${ }^{91} \mathrm{~B}+\mathrm{P} ;{ }^{87} \mathrm{OHPP}{ }^{92}$ (Oral-Health Promotion Program: based on screening children's teeth, supervised tooth-brushing with fluoride dentifrices, and dietary control); Hall technique; and $\mathrm{ART}^{43,93,94}$ have been shown to be the most costeffective tools for provision of optimal oral-health care and management of caries lesions. Therefore, the implementation of tailored and individual oral healthcare packages would be a desirable approach for LACCs considering the sociodemographic characteristics of this region.

The findings of this review showed selective caries tissue removal limited to softened dentin 
over the pulpal roof was the most cost-effective strategy for the management of deep caries lesions, particularly in high-risk individuals. ${ }^{95,96}$ However, it may take some time for professionals in LACCs to accept and incorporate such changes, with one study showing that older dentists in public services in southern Brazil were more likely to choose strategies with higher risk of pulp compromise or poorer prognosis for the management of deep caries lesions when compared to their younger colleagues, possibly because the latter had been educated in a more conservative manner. ${ }^{97}$

In case of root caries lesions, mechanical removal of dental biofilm with the help of 5000 ppm F dentifrices has been shown to exhibit high efficacy in older adults. ${ }^{23} \mathrm{SDF}$ is also considered to be an excellent costeffective resource in case of such lesions, ${ }^{98}$ although there are currently no standardized guidelines for its effective use in arresting dentin lesions in primary and permanent dentition.

From the perspective of oral-health practitioners in LACCs as well as educational institutions and national dental associations in the region, what are the specific actions for the management of dental caries and dental caries lesions in this geographic region? Firstly, continuing education through regular updates of clinical training is a crucial part of our responsibility to promote change in the profession and curriculum. Secondly, reviewing and adapting programs that emphasize preventive tasks, improve public oral health, promote the use of materials and techniques adapted to the personal needs of the patients, and favor evidence-based dentistry is essential. Therefore, dental education and practice as a whole must be adapted to the current reality of LACCs.

Oral-health care systems differ in structure and scope around the world and also within LACCs, and these differences are influenced by various economic and political factors. Despite the efforts of many countries to build national policies that make primary health care accessible to the whole population; this goal has not been achieved in most LACCs as yet. Proper social and health data about the prevalence and severity of dental caries, which are essential for health policy-makers, are still not available in all countries. ${ }^{99}$ Decisions on how to manage and control caries lesions should be guided by clinical protocols based on the available evidence on effectiveness as well as a comprehensive understanding of the local oral-health scenario and available resources. ${ }^{100}$ Strategies should be effective, affordable, and should contribute to providing equity in access to oralhealth services. Assessment of the cost-effectiveness of caries management strategies should take into consideration initial treatment costs as well as those associated with success/failure rates and the possible need for retreatment.

\section{Conclusions}

a. Individualized treatment based on the risk management, ${ }^{101}$ of the disease process and on the control of the caries lesion activity/ development is important for adequate and effective condition control.

b. Daily use of fluoride dentifrices (10001500 ppm F) is highly recommended as a preventive and therapeutic strategy for the management of dental caries lesions. Some studies have recommended use of fluoride dentifrices at concentrations of 5000 ppm or SDF for the management of root caries. Pit and fissure sealants as well as resin infiltrants may be used for the management of non-cavitated lesions.

c. Restorative treatments that focus on filling cavities only without controlling the disease are not beneficial. Individuals should always be motivated and encouraged to improve their oral hygiene and acquire healthy dietary habits. ${ }^{14}$

d. Restorative treatments allowing maximum preservation of tooth structure should be indicated whenever lesion progression cannot be arrested by non-invasive/micro-invasive interventions, ${ }^{11}$ such as in the case of active cavitated lesions that cannot be cleaned. The Hall technique is recommended as a mixed non-invasive and restorative strategy for primary molars. ${ }^{42,43,44,102}$ Selective removal of caries tissues over the pulp chamber roof (up to leathery/firm dentin in case of shallow/ 
moderate deep lesions or to soft dentin in case of deep lesions) should be carried out when necessary. ${ }^{11}$

e. Selective removal of caries tissues up to soft dentin over the pulp chamber roof followed by definitive restoration in one session must be the recommended treatment of choice for symptomless deep caries lesions. ${ }^{11,53,56,57,58,59}$

f. ART restorations exhibit higher survival rates over time, especially for single-surface restorations, in both primary and permanent teeth. This method may be considered as a feasible strategy for places without a proper clinical set-up or at public health systems/ private practices with budget restrictions. However, the use of high-quality standardized materials is necessary to ensure restoration longevity. $22,50,51,52,64,68,69,70,71,72$

g. There is limited evidence in support of the direct placement of restorative materials over evident cavitated lesions (shallow to moderate depth) without prior caries tissue removal in LACCs, ${ }^{45,46,48}$ and further well-designed studies are necessary in order for a definitive recommendation to be made.

h. Invasive restorative treatments should be postponed in favor of restoration repair whenever possible. Moreover, replacement of restorations should be discouraged or only recommended in the absence of other viable options. Shorter intervals between recall visits should be adopted after taking the patient's caries risk and/or activity into consideration to allow repair of any restoration defects in a timely manner.

i. As per the International Association for Dental Research (IADR), dental amalgam continues to present adequate longevity and cost-effectiveness, despite development of new adhesive and aesthetic restorative materials. Therefore, when other restorative materials are less optimal due to clinical, economic, and practical reasons, amalgam should be considered as an acceptable option for the general population provided they do not exhibit any allergies to its constituents or present with severe renal diseases. As per the IADR, currently there is insufficient evidence in support of a causal relationship between mercury from amalgam restorations and adverse systemic health outcomes. Furthermore, the available evidence does not preclude the use of amalgam as a tooth restoration material nor suggest the need for replacement of preexisting amalgam restorations. ${ }^{103}$ However, we do acknowledge that current evidence suggests that both amalgam and resin composites exhibit equal clinical success and that it is fair to state that the philosophy behind amalgam restorations does not comply with the paradigm of Minimally Invasive Dentistry. In this context, amalgam should not be considered as a goldstandard restorative material.

i. Non-invasive vital pulp therapies such as direct and indirect pulp capping have been shown clinical and radiographically to be useful for the treatment of primary and permanent (mature and immature) teeth with deep caries lesions. ${ }^{74}$

k. Pulpotomy procedures have been extensively employed as a routine treatment option e for primary teeth with reversible pulpal inflammation. Moreover, pulpotomies have exhibited high success rates when used for the management of pulp exposure in deep caries lesions in permanent teeth. Therefore, this procedure is currently considered as a suitable substitute for root canal treatment, even in cases diagnosed with irreversible pulpitis, as it offers time, clinical, and cost-effectiveness advantages. ${ }^{104,105}$

I. Despite evidence from randomized controlled trials and systematic reviews, the choice of strategies for caries lesion management at the population level must take into consideration the cost-effectiveness, available financial and technical resources, and the needs of public health systems and private practices. Moreover, there is a lack of pragmatic data confirming whether the evidence provided by randomized controlled trials is reproducible in real settings where dental treatments are delivered by clinicians (such as public health systems and private practices). 


\section{Recommendations}

a. Let's go back to the basics: Before opting for new alternatives for the treatment of dental caries, consideration of the biological processes of dental caries development will allow the clinician to make treatment decisions with the expected outcome.

b. Consider the sociodemographic context: Various attractive therapeutic options such as novel biomaterials or techniques may be unavailable in some LACCs, and this must be taken into consideration by clinicians when selecting a treatment strategy.

c. Always analyze the individual patient's needs: the target affected population typically belongs to the lower socioeconomic strata in developing LACCs and, therefore, may be unable to access a wide range of treatment options. In such situations, the preservation of public health and assurance of oral-health care provision must supersede any secondary outcomes.

d. The gap between industry, academia, and the clinical sector must be bridged in LACCs: International as well as local industries in LACCs must monitor the clinical outcomes of various treatment options and, where possible, develop new materials to further improve the caries lesion management process. These developments must be carried out in collaboration with academic organizations under strict ethical control, and well-trained clinicians may contribute to the process through the provision of pragmatic information.

e. Generate high-quality scientific and pragmatic evidence: The present manuscript highlights the need for more high-quality scientific evidence adapted to the local geographical region. Moreover, it is also complemented by the recognition of severe deficiencies in the existing oral public health systems of LACCs including inequalities in access to services among the general population, financial limitations of the governments, and lack of standardized clinical guidelines for adequate preventive and restorative treatment of caries lesions adapted to the local geographical and cultural context.

f. Never stop learning: Dental caries management is a dynamic process characterized by the development of new emerging trends replacing dated paradigms. As a result, it is imperative that clinicians equip themselves with the most recent, reliable evidence so as to prepare themselves for the adoption of new treatment alternatives as and when they become locally available.

\section{Acknowledgments}

This paper was prepared for the consensus meeting titled "Dental Caries Prevalence, Prospects and Challenges for LACC", promoted by the Latin American Oral Health Association and Colgate Palmolive Co. with the support of the Federación Odontológica Latinoamericana, Sociedade Brasileira de Pesquisa Odontológica (SBPqO/Brazilian Division of IADR), and the participation of experts from the region including representatives from national, regional and international dental associations. All participants had the opportunity to review the manuscript and make their own contributions. This paper contributed to the summary and final recommendations of the Dental Caries Regional Consensus.

\section{References}

1. Machiulskiene V, Campus G, Carvalho JC, Dige I, Ekstrand KR, Jablonski-Momeni A, et al. Terminology of dental caries and dental caries management: consensus report of a workshop organized by ORCA and Cariology Research Group of IADR. Caries Res. 2020;54(1):7-14. https://doi.org/10.1159/000503309

2. Featherstone JD. Dental caries: a dynamic disease process. Aust Dent J. 2008 Sep;53(3):286-91. https://doi.org/10.1111/j.18347819.2008.00064.x 
3. Slayton RL, Urquhart O, Araujo MW, Fontana M, Guzmán-Armstrong S, Nascimento MM, et al. Evidence-based clinical practice guideline on nonrestorative treatments for carious lesions: A report from the American Dental Association. J Am Dent Assoc. 2018 Oct;149(10):837-849.e19. https://doi.org/10.1016/j.adaj.2018.07.002

4. Bjørndal L, Simon S, Tomson PL, Duncan HF. Management of deep caries and the exposed pulp. Int Endod J. 2019 Jul;52(7):949-73. https://doi.org/10.1111/iej.13128

5. Ramos-Jorge J, Alencar BM, Pordeus IA, Soares ME, Marques LS, Ramos-Jorge ML, et al. Impact of dental caries on quality of life among preschool children: emphasis on the type of tooth and stages of progression. Eur J Oral Sci. 2015 Apr;123(2):88-95. https://doi. org/10.1111/eos.12166

6. Kassebaum NJ, Bernabé E, Dahiya M, Bhandari B, Murray CJ, Marcenes W. Global burden of untreated caries: a systematic review and metaregression. J Dent Res. 2015 May;94(5):650-8. https://doi.org/10.1177/0022034515573272

7. Singh H, Maharaj RG, Naidu R. Oral health among the elderly in 7 Latin American and Caribbean cities, 1999-2000: a cross-sectional study. BMC Oral Health. 2015 Apr;15(1):46. https://doi.org/10.1186/s12903-015-0030-x

8. Carrer FCA, Pucca Junior GA, coords. Observatorio Iberoamericano de políticas públicas en salud bucal: construyendo un bloque por más salud bucal. São Paulo: Faculdade de Odontologia da USP; 2018.

9. Yee R, Sheiham A. The burden of restorative dental treatment for children in Third World countries. Int Dent J. 2002 Feb;52(1):1-9. https://doi.org/10.1111/j.1875-595X.2002.tb00589.x

10. Lee H, Chalmers NI, Brow A, Boynes S, Monopoli M, Doherty M, et al. Person-centered care model in dentistry. BMC Oral Health. 2018 Nov; 18(1):198. https://doi.org/10.1186/s12903-018-0661-9

11. Schwendicke F, Frencken JE, Biørndal L, Maltz M, Manton DJ, Ricketts D, et al. Managing carious lesions: consensus recommendations on carious tissue removal. Adv Dent Res. 2016 May;28(2):58-67. https://doi.org/10.1177/0022034516639271

12. Banerjee A, Frencken JE, Schwendicke F, Innes NP. Contemporary operative caries management: consensus recommendations on minimally invasive caries removal. Br Dent J. 2017 Aug;223(3):215-22. https://doi.org/10.1038/sj.bdj.2017.672

13. Schwendicke F, Splieth C, Breschi L, Banerjee A, Fontana M, Paris S, et al. When to intervene in the caries process? An expert Delphi consensus statement. Clin Oral Investig. 2019 Oct;23(10):3691-703. https://doi.org/10.1007/s00784-019-03058-w

14. Ricomini Filho AP, Chávez BA, Giacaman RA, Frazão P, Cury JA. Community interventions and strategies for caries control in Latin American and Caribbean countries. Braz Oral Res. 2021;35(suppl 1):e054. https://doi.org/10.1590/1807-3107bor-2021.vol35.0054

15. Hausen H, Seppa L, Poutanen R, Niinimaa A, Lahti S, Kärkkäinen S, et al. Noninvasive control of dental caries in children with active initial lesions. A randomized clinical trial. Caries Res. 2007;41(5):384-91. https://doi.org/10.1159/000104797

16. Thylstrup A, Bruun C, Holmen L. In vivo caries models_mechanisms for caries initiation and arrestment. Adv Dent Res. 1994 Jul;8(2):144-57. https://doi.org/10.1177/08959374940080020401

17. Hujoel PP, Hujoel ML, Kotsakis GA. Personal oral hygiene and dental caries: A systematic review of randomised controlled trials. Gerodontology. 2018 Dec;35(4):282-9. https://doi.org/10.1111/ger.12331

18. Frencken JE, Peters MC, Manton DJ, Leal SC, Gordan VV, Eden E. Minimally Intervention Dentistry (MID) for managing dental caries: a review. Int Dent J. 2012;62(5):223-43. https://doi.org/10.1111/idj.12007

19. Petersson GH, Bratthall D. The caries decline: a review of reviews. Eur J Oral Sci. 1996 Aug; 104(4 ( Pt 2)):436-43. https://doi. org/10.1111/j.1600-0722.1996.tb00110.x

20. Walsh T, Worthington HV, Glenny AM, Marinho VC, Jeroncic A. Fluoride toothpastes of different concentrations for preventing dental caries. Cochrane Database Syst Rev. 2019 Mar;3(3):CD007868. https://doi.org/10.1002/14651858.CD007868.pub3

21. Nyvad B, Fejerskov O. Active root surface caries converted into inactive caries as a response to oral hygiene. Scand J Dent Res. 1986 Jun;94(3):281-4. https://doi.org/10.1111/i.1600-0722.1986.tb01765.x PMID:3461550

22. Mijan M, Amorim RG, Leal SC, Mulder J, Oliveira L, Creugers NH, et al. The 3.5-year survival rates of primary molars treated according to three treatment protocols: a controlled clinical trial. Clin Oral Investig. 2014 May;18(4):1061-9. https://doi.org/10.1007/s00784-0131077-1

23. León S, González K, Hugo FN, Gambetta-Tessini K, Giacaman RA. High fluoride dentifrice for preventing and arresting root caries in community-dwelling older adults: A randomized controlled clinical trial. J Dent. 2019 Jul;86:110-7. https://doi.org/10.1016/i. ident.2019.06.002

24. Wierichs RJ, Meyer-Lueckel H. Systematic review on noninvasive treatment of root caries lesions. J Dent Res. 2015 Feb;94(2):261-71. https://doi.org/10.1177/0022034514557330

25. Urquhart O, Tampi MP, Pilcher L, Slayton RL, Araujo MW, Fontana M, et al. Nonrestorative treatments for caries: systematic review and network meta-analysis. J Dent Res. 2019 Jan;98(1):14-26. https://doi.org/10.1177/0022034518800014

26. Gao SS, Zhang S, Mei ML, Lo EC, Chu CH. Caries remineralisation and arresting effect in children by professionally applied fluoride treatment: a systematic review. BMC Oral Health. 2016 Feb;16(1):12. https://doi.org/10.1186/s12903-016-0171-6 
27. Chibinski AC, Wambier LM, Feltrin J, Loguercio AD, Wambier DS, Reis A. Silver diamine fluoride has efficacy in controlling caries progression in primary teeth: a systematic review and meta-analysis. Caries Res. 2017;51(5):527-41. https://doi.org/10.1159/000478668

28. Hendre AD, Taylor GW, Chávez EM, Hyde S. A systematic review of silver diamine fluoride: effectiveness and application in older adults. Gerodontology. 2017 Dec;34(4):411-9. https://doi.org/10.1111/ger.12294

29. Oliveira BH, Cunha-Cruz J, Rajendra A, Niederman R. Controlling caries in exposed root surfaces with silver diamine fluoride: $A$ systematic review with meta-analysis. J Am Dent Assoc. 2018 Aug;149(8):671-679.el. https://doi.org/10.1016/j.adaj.2018.03.028

30. Wu L, Geng K, Gao Q. Early caries preventive effects of casein phosphopeptide-amorphous calcium phosphate (CPP-ACP) compared with conventional fluorides: A meta-analysis. Oral Health Prev Dent. 2019;17(6):495-503. https://doi.org/10.3290/i.ohpd.a43637

31. Wang Y, Li J, Sun W, Li H, Cannon RD, Mei L. Effect of non-fluoride agents on the prevention of dental caries in primary dentition: a systematic review. PLoS One. 2017 Aug;12(8):e0182221. https://doi.org/10.1371/journal.pone.0182221

32. Meyer-Lueckel H, Machiulskiene V, Giacaman RA. How to intervene in the root caries process? Systematic review and meta-analyses. Caries Res. 2019;53(6):599-608. https://doi.org/10.1159/000501588

33. Premnath P, John J, Manchery N, Subbiah GK, Nagappan N, Subramani P. Effectiveness of theobromine on enamel remineralization: $A$ comparative in-vitro study. Cureus. 2019 Sep;11(9):e5686. https://doi.org/10.7759/cureus.5686

34. Carrouel F, Viennot S, Ottolenghi L, Gaillard C, Bourgeois D. Nanoparticles as anti-microbial, anti-inflammatory, and remineralizing agents in oral care cosmetics: A review of the current situation. Nanomaterials (Basel). 2020 Jan;10(1):140. https://doi.org/10.3390/ nano10010140

35. Ahovuo-Saloranta A, Forss H, Walsh T, Nordblad A, Mäkelä M, Worthington HV. Pit and fissure sealants for preventing dental decay in permanent teeth. Cochrane Database Syst Rev. 2017 Jul;7(7):CD001830. https://doi.org/10.1002/14651858.CD001830.pub5

36. Griffin SO, Oong E, Kohn W, Vidakovic B, Gooch BF, Bader J, et al. The effectiveness of sealants in managing caries lesions. J Dent Res. 2008 Feb;87(2):169-74. https://doi.org/10.1177/154405910808700211

37. Wright JT, Tampi MP, Graham L, Estrich C, Crall JJ, Fontana M, et al. Sealants for preventing and arresting pit-and-fissure occlusal caries in primary and permanent molars: a systematic review of randomized controlled trials-a report of the American Dental Association and the American Academy of Pediatric Dentistry. J Am Dent Assoc. 2016 Aug;147(8):631-645.e18. https://doi.org/10.1016/i. adaj.2016.06.003

38. Dorri M, Dunne SM, Walsh T, Schwendicke F. Micro-invasive interventions for managing proximal dental decay in primary and permanent teeth. Cochrane Database Syst Rev. 2015 Nov; 11(11):CD010431. https://doi.org/10.1002/14651858.CD010431.pub2

39. Faghihian R, Shirani M, Tarrahi MJ, Zakizade M. Efficacy of the resin infiltration technique in preventing initial caries progression: a systematic review and meta-analysis. Pediatr Dent. 2019 Mar;41(2):88-94.

40. Strijp G, van Loveren C. No removal and inactivation of carious tissue: non-restorative cavity control. Monogr Oral Sci. 2018;27:124-36. https://doi.org/10.1159/000487839

41. Corralo DJ, Maltz M. Clinical and ultrastructural effects of different liners/restorative materials on deep carious dentin: a randomized clinical trial. Caries Res. 2013;47(3):243-50. https://doi.org/10.1159/000345648

42. Tedesco TK, Gimenez T, Floriano I, Montagner AF, Camargo LB, Calvo AF, et al. Scientific evidence for the management of dentin caries lesions in pediatric dentistry: A systematic review and network meta-analysis. PLoS One. 2018 Nov;13(11):e0206296. https://doi. org/10.1371/journal.pone.0206296

43. Badar SB, Tabassum S, Khan FR, Ghafoor R. Effectiveness of Hall technique for primary carious molars: systematic review and metaanalysis. Int J Clin Pediatr Dent. 2019 Sep-Oct;12(5):445-52. https://doi.org/10.5005/ip-journals-10005-1666

44. Santamaría RM, Abudrya MH, Gül G, Mourad MS, Gomez GF, Zandona AG. How to intervene in the caries process: dentin caries in primary teeth. Caries Res. 2020;54(4):306-23. https://doi.org/10.1159/000508899

45. Hesse D, Bonifácio CC, Mendes FM, Braga MM, Imparato JC, Raggio DP. Sealing versus partial caries removal in primary molars: a randomized clinical trial. BMC Oral Health. 2014 May;14(1):58. https://doi.org/10.1186/1472-6831-14-58

46. Dias KR, Andrade CB, Wait TT, Chamon R, Ammari MM, Soviero VM, et al. Efficacy of sealing occlusal caries with a flowable composite in primary molars: A 2-year randomized controlled clinical trial. J Dent. 2018 Jul;74:49-55. https://doi.org/10.1016/i.jdent.2018.05.014

47. Bakhshandeh A, Qvist V, Ekstrand KR. Sealing occlusal caries lesions in adults referred for restorative treatment: 2-3 years of follow-up. Clin Oral Investig. 2012 Apr;16(2):521-9. https://doi.org/10.1007/s00784-011-0549-4

48. Alves LS, Giongo FC, Mua B, Martins VB, Barbachan E Silva B, Qvist V, et al. A randomized clinical trial on the sealing of occlusal carious lesions: 3-4-year results. Braz Oral Res. 2017 Jun;31(0):e44. https://doi.org/10.1590/1807-3107bor-2017.vol31.0044

49. Innes NP, Frencken JE, Biørndal L, Maltz M, Manton DJ, Ricketts D, et al. Managing carious lesions: consensus recommendations on terminology. Adv Dent Res. 2016 May;28(2):49-57. https://doi.org/10.1177/0022034516639276

50. Amorim RG, Frencken JE, Raggio DP, Chen X, Hu X, Leal SC. Survival percentages of atraumatic restorative treatment (ART) restorations and sealants in posterior teeth: an updated systematic review and meta-analysis. Clin Oral Investig. 2018 Nov;22(8):2703-25. https:// doi.org/10.1007/s00784-018-2625-5 
51. Moura MS, Sousa GP, Brito MH, Silva MC, Lima MD, Moura LF, et al. Does low-cost GIC have the same survival rate as high-viscosity GIC in atraumatic restorative treatments? A RCT. Braz Oral Res. 2020 Jan;33:e125. https://doi.org/10.1590/1807-3107bor-2019. vol33.0125

52. Olegário IC, Ladewig NM, Hesse D, Bonifácio CC, Braga MM, Imparato JC, et al. Is it worth using low-cost glass ionomer cements for occlusal ART restorations in primary molars? 2-year survival and cost analysis of a Randomized clinical trial. J Dent. 2020 Oct;101:103446. https://doi.org/10.1016/i.jdent.2020.103446

53. Franzon R, Guimarães LF, Magalhães CE, Haas AN, Araujo FB. Outcomes of one-step incomplete and complete excavation in primary teeth: a 24 -month randomized controlled trial. Caries Res. 2014;48(5):376-83. https://doi.org/10.1159/000357628

54. Franzon R, Opdam NJ, Guimarães LF, Demarco FF, Casagrande L, Haas AN, et al. Randomized controlled clinical trial of the 24 -months survival of composite resin restorations after one-step incomplete and complete excavation on primary teeth. J Dent. 2015 Oct;43(10):1235-41. https://doi.org/10.1016/i.jdent.2015.07.011

55. Pedrotti D, Cavalheiro CP, Casagrande L, Araújo FB, Imparato JCP, Rocha RO, et al. Does selective carious tissue removal of soft dentin increase the restorative failure risk in primary teeth?: Systematic review and meta-analysis. J Am Dent Assoc. 2019 Jul;150(7):582-590. el. https://doi.org/10.1016/i.adaj.2019.02.018

56. Maltz M, Koppe B, Jardim JJ, Alves LS, Paula LM, Yamaguti PM, et al. Partial caries removal in deep caries lesions: a 5-year multicenter randomized controlled trial. Clin Oral Investig. 2018 Apr;22(3):1337-43. https://doi.org/10.1007/s00784-017-2221-0

57. Barros MM, Rodrigues MIQ, Muniz FW, Rodrigues LK. Selective, stepwise, or nonselective removal of carious tissue: which technique offers lower risk for the treatment of dental caries in permanent teeth? A systematic review and meta-analysis. Clin Oral Investig. 2020 Feb;24(2):521-32. https://doi.org/10.1007/s00784-019-03114-5

58. Casagrande L, Seminario AT, Correa MB, Werle SB, Maltz M, Demarco FF, et al. Longevity and associated risk factors in adhesive restorations of young permanent teeth after complete and selective caries removal: a retrospective study. Clin Oral Investig. 2017 Apr;21(3):847-55. https://doi.org/10.1007/s00784-016-1832-1

59. Jardim JJ, Mestrinho HD, Koppe B, Paula LM, Alves LS, Yamaguti PM, et al. Restorations after selective caries removal: 5-Year randomized trial. J Dent. 2020 Aug;99:103416. https://doi.org/10.1016/i.jdent.2020.103416

60. Opdam NJ, Sande FH, Bronkhorst E, Cenci MS, Bottenberg P, Pallesen U, et al. Longevity of posterior composite restorations: a systematic review and meta-analysis. J Dent Res. 2014 Oct;93(10):943-9. https://doi.org/10.1177/0022034514544217

61. Ruiz LF, Nicoloso GF, Franzon R, Lenzi TL, Araujo FB, Casagrande L. Repair increases the survival of failed primary teeth restorations in high-caries risk children: a university-based retrospective study. Clin Oral Investig. 2020 Jan;24(1):71-7. https://doi.org/10.1007/ s00784-019-02899-9

62. Fernández E, Martín J, Vildósola P, Oliveira Junior OB, Gordan V, Mior I, et al. Can repair increase the longevity of composite resins? Results of a 10-year clinical trial. J Dent. 2015 Feb;43(2):279-86. https://doi.org/10.1016/i.jdent.2014.05.015

63. Moncada G, Fernández E, Mena K, Martin J, Vildósola P, De Oliveira Junior OB, et al. Seal, replacement or monitoring amalgam restorations with occlusal marginal defects? Results of a 10-year clinical trial. J Dent. 2015 Nov;43(11):1371-8. https://doi.org/10.1016/i. ¡dent.2015.07.012

64. Menezes JP, Rosenblatt A, Medeiros E. Clinical evaluation of atraumatic restorations in primary molars: a comparison between 2 glass ionomer cements. J Dent Child (Chic). 2006 May-Aug;73(2):91-7.

65. Martignon S, Ekstrand KR, Gomez J, Lara JS, Cortes A. Infiltrating/sealing proximal caries lesions: a 3-year randomized clinical trial. J Dent Res. 2012 Mar;91(3):288-92. https://doi.org/10.1177/0022034511435328

66. Jorge RC, Ammari MM, Soviero VM, Souza IP. Randomized controlled clinical trial of resin infiltration in primary molars: 2 years followup. J Dent. 2019;90:103184. https://https://doi.org/10.1016/i.jident.2019.103184

67. Sarti CS, Vizzotto MB, Filgueiras LV, Bonifácio CC, Rodrigues JA. Two-year split-mouth randomized controlled clinical trial on the progression of proximal carious lesions on primary molars after resin infiltration. Pediatr Dent. 2020 Mar;42(2):110-5.

68. Cefaly DF, Barata TJ, Bresciani E, Fagundes TC, Lauris JR, Navarro MF. Clinical evaluation of multiple-surface ART restorations: 12 month follow-up. J Dent Child (Chic). 2007 Sep-Dec;74(3):203-8.

69. Zanata RL, Fagundes TC, Freitas MC, Lauris JR, Navarro MF. Ten-year survival of ART restorations in permanent posterior teeth. Clin Oral Investig. 2011 Apr;15(2):265-71. https://doi.org/10.1007/s00784-009-0378-x

70. Hilgert LA, Amorim RG, Leal SC, Mulder J, Creugers NH, Frencken JE. Is high-viscosity glass-ionomer-cement a successor to amalgam for treating primary molars? Dent Mater. 2014 Oct;30(10):1172-8. https://doi.org/10.1016/i.dental.2014.07.010

71. Molina GF, Faulks D, Mazzola I, Cabral RJ, Mulder J, Frencken JE. Three-year survival of ART high-viscosity glass-ionomer and resin composite restorations in people with disability. Clin Oral Investig. 2018 Jan;22(1):461-7. https://doi.org/10.1007/s00784-017-2134-y

72. Vollú AL, Rodrigues GF, Rougemount Teixeira RV, Cruz LR, Massa GS, Moreira JPL, et al. Efficacy of $30 \%$ silver diamine fluoride compared to atraumatic restorative treatment on dentine caries arrestment in primary molars of preschool children: a 12-months parallel randomized controlled clinical trial. J Dent. 2019 Sep;88:103165. https://doi.org/10.1016/i.jdent.2019.07.003 
73. Ribeiro CC, Baratieri LN, Perdigão J, Baratieri NM, Ritter AV. A clinical, radiographic, and scanning electron microscopic evaluation of adhesive restorations on carious dentin in primary teeth. Quintessence Int. 1999 Sep;30(9):591-9.

74. Garrocho-Rangel A, Quintana-Guevara K, Vázquez-Viera R, Arvizu-Rivera JM, Flores-Reyes H, Escobar-García DM, et al. Bioactive tricalcium silicate-based dentin substitute as an indirect pulp capping material for primary teeth: a 12-month follow-up. Pediatr Dent. 2017 Sep;39(5):377-82.

75. Rosa WL, Lima VP, Moraes RR, Piva E, Silva AF. Is a calcium hydroxide liner necessary in the treatment of deep caries lesions? A systematic review and meta-analysis. Int Endod J. 2019 May;52(5):588-603. https://doi.org/10.1111/iej.13034

76. Santos PS, Pedrotti D, Braga MM, Rocha RO, Lenzi TL. Materials used for indirect pulp treatment in primary teeth: a mixed treatment comparisons meta-analysis. Braz Oral Res. 2017 Dec;31(0):e101. https://doi.org/10.1590/1807-3107/2017.vol31.0101

77. Brignardello-Petersen R. Calcium hydroxide seems to not result in important benefits compared with other liners for treating deep carious lesions in primary teeth. J Am Dent Assoc. 2019 May;150(5):e55. https://doi.org/10.1016/j.adaj.2019.01.013

78. Duncan HF, Galler KM, Tomson PL, Simon S, El-Karim I, Kundzina R, et al. European Society of Endodontology position statement: management of deep caries and the exposed pulp. Int Endod J. 2019 Jul;52(7):923-34. https://doi.org/10.1111/iej.13080

79. Garrocho-Rangel A, Esparza-Villalpando V, Pozos-Guillen A. Outcomes of direct pulp capping in vital primary teeth with cariously and non-cariously exposed pulp: a systematic review. Int J Paediatr Dent. 2020 Sep;30(5):536-46. https://doi.org/10.1111/ipd.12633

80. Brizuela C, Ormeño A, Cabrera C, Cabezas R, Silva Cl, Ramírez V, et al. Direct pulp capping with calcium hydroxide, mineral trioxide aggregate, and biodentine in permanent young teeth with caries: a randomized clinical trial. J Endod. 2017 Nov;43(11):1776-80. https:// doi.org/10.1016/i.joen.2017.06.031

81. Marending M, Attin T, Zehnder M. Treatment options for permanent teeth with deep caries. Swiss Dent J. 2016;126(11):1007-27.

82. Aguilar $P$, Linsuwanont P. Vital pulp therapy in vital permanent teeth with cariously exposed pulp: a systematic review. J Endod. 2011 May;37(5):581-7. https://doi.org/10.1016/i.joen.2010.12.004

83. Elmsmari F, Ruiz XF, Miró Q, Feijoo-Pato N, Durán-Sindreu F, Olivieri JG. Outcome of partial pulpotomy in cariously exposed posterior permanent teeth: A systematic review and meta-analysis. J Endod. 2019 Nov;45(11):1296-1306.e3. https://doi.org/10.1016/i. joen.2019.07.005

84. Taha NA, Abdelkhader SZ. Outcome of full pulpotomy using Biodentine in adult patients with symptoms indicative of irreversible pulpitis. Int Endod J. 2018 Aug;51(8):819-28. https://doi.org/10.1111/iej.12903 PMID:29397003

85. Gimenez T, Bispo BA, Souza DP, Viganó ME, Wanderley MT, Mendes FM, et al. Does the decline in caries prevalence of Latin American and Caribbean children continue in the new century? Evidence from systematic review with meta-analysis. PLoS One. 2016 Oct;11(10):e0164903. https://doi.org/10.1371/journal.pone.0164903

86. Mariño R, Fajardo J, Morgan M. Cost-effectiveness models for dental caries prevention programmes among Chilean schoolchildren. Community Dent Health. 2012 Dec;29(4):302-8. https://doi.org/10.1922/CDH_2893Marino07

87. Homer T, Maguire A, Douglas GV, Innes NP, Clarkson JE, Wilson N, et al. Cost-effectiveness of child caries management: a randomised controlled trial (FiCTION trial). BMC Oral Health. 2020 Feb;20(1):45. https://doi.org/10.1186/s12903-020-1020-1

88. Neidell M, Shearer B, Lamster IB. Cost-effectiveness analysis of dental sealants versus fluoride varnish in a school-based setting. Caries Res. 2016;50 Suppl 1:78-82. https://doi.org/10.1159/000439091

89. Khouja T, Smith KJ. Cost-effectiveness analysis of two caries prevention methods in the first permanent molar in children. J Public Health Dent. 2018 Mar;78(2):118-26. https://doi.org/10.1111/iphd.12246

90. Warren E, Curtis BH, Jia N, Evans RW. The caries management system: updating cost-effectiveness with 4-year post-trial data. Int J Technol Assess Health Care. 2016 Jan;32(3):107-15. https://doi.org/10.1017/\$0266462316000246

91. Frencken JE, Holmgren CJ, Palenstein Helderman WH. Basic package of oral care. Geneva: WHO Collaborating Centre for Oral Health Care Planning and Future Scenarios; Nijmegen University of Nijmegen; 2002.

92. Fraihat N, Madae'en S, Bencze Z, Herczeg A, Varga O. Clinical effectiveness and cost-effectiveness of oral-health promotion in dental caries prevention among children: systematic review and meta-analysis. Int J Environ Res Public Health. 2019 Jul;16(15):2668. https://doi. org/10.3390/ijerph16152668

93. Schwendicke F, Stolpe M, Innes N. Conventional treatment, Hall Technique or immediate pulpotomy for carious primary molars: a costeffectiveness analysis. Int Endod J. 2016 Sep;49(9):817-26. https://doi.org/10.1111/iej.12537

94. Dorri M, Martinez-Zapata MJ, Walsh T, Marinho VC, Sheiham Deceased A, Zaror C. Atraumatic restorative treatment versus conventional restorative treatment for managing dental caries. Cochrane Database Syst Rev. 2017 Dec;12(12):CD008072. https://doi. org/10.1002/14651858.CD008072.pub2

95. Schwendicke F, Paris S, Stolpe M. Cost-effectiveness of caries excavations in different risk groups - a micro-simulation study. BMC Oral Health. 2014 Dec;14(1):153. https://doi.org/10.1186/1472-6831-14-153

96. Emara R, Krois J, Schwendicke F. Maintaining pulpal vitality: cost-effectiveness analysis on carious tissue removal and direct pulp capping. J Dent. 2020 May;96:103330. https://doi.org/10.1016/i.jdent.2020.103330 
Management of dental caries lesions in Latin American and Caribbean countries

97. Weber CM, Alves LS, Maltz M. Treatment decisions for deep carious lesions in the Public Health Service in Southern Brazil. J Public Health Dent. 2011;71(4):265-70. https://doi.org/10.1111/j.1752-7325.2011.00258.x

98. Schwendicke F, Göstemeyer G. Cost-effectiveness of root caries preventive treatments. J Dent. 2017 Jan;56:58-64. https://doi. org/10.1016/i.jdent.2016.10.016

99. Paiva SM, Abreu-Placeres N, Camacho MEI, Frias AC, Tello G, Perazzo MF, et al. Dental caries experience and its impact on oral healthrelated quality of life in Latin American and Caribbean countries. Braz Oral Res. 2021;35(suppl 1):e052. https://doi.org/10.1590/18073107bor-2021.vol35.0052

100. Sampaio FC, Bönecker M, Paiva SM, Martignon S, Ricomini Filho AP, Pozos-Guillen A, et al. Dental caries prevalence, prospects, and challenges for Latin American and Caribbean countries: summary and final recommendations from a Regional Consensus. Braz Oral Res. 2021;35(suppl 1):e056. https://doi.org/10.1590/1807-3107bor-2021.vol35.0056

101. Martignon S, Roncalli AG, Alvarez E, Aránguiz V, Feldens CA, Buzalaf MAR. Risk factors for dental caries in Latin American and Caribbean countries. Braz Oral Res. 2021;35(suppl 1):e053. https://doi.org/10.1590/1807-3107bor-2021.vol35.0053

102. Ebrahimi M, Shirazi AS, Afshari E. Success and behavior during atraumatic restorative treatment, the Hall technique, and the stainless steel crown technique for primary molar teeth. Pediatr Dent. 2020 May;42(3):187-92.

103. Ajiboye AS, Mossey PA; IADR Science Information Committee. Fox CH. International Association for Dental Research Policy and Position Statements on the Safety of Dental Amalgam. J Dent Res. 2020;99(7):763-8. https://doi.org/10.1177/0022034520915878

104. Gonzalez-Lara A, Ruiz-Rodriguez MS, Pierdant-Perez M, Garrocho-Rangel JA, Pozos-Guillen AJ. Zinc oxide-eugenol pulpotomy in primary teeth: A 24 -month follow-up. J Clin Pediatr Dent. 2016;40(2):107-12. https://doi.org/10.17796/1053-4628-40.2.107

105. Li Y, Sui B, Dahl C, Bergeron B, Shipman P, Niu L, et al. Pulpotomy for carious pulp exposures in permanent teeth: A systematic review and meta-analysis. J Dent. 2019 May;84:1-8. https://doi.org/10.1016/i.jdent.2019.03.010 